Lessons from the Field

\title{
Perioperative Nursing Training in Rwanda in Partnership with American Universities: The Journey So Far
}

Joselyne Mukantwari ${ }^{1 * 3}$, Lilian Omondi1,2, David Ryamukuru ${ }^{1}$

${ }^{1}$ General Nursing Departmenet, Shool of Nursing and Midwifery, College of Medicine and Health Sciences, University of Rwanda, Kigali, Rwanda

${ }^{2}$ Human Resource for Health, Ministry of Health, Kigali, Rwanda

${ }^{3}$ Faculty of Health Sciences, Arthur Labatt Family School of Nursing, University of Western

Ontario, London, Ontario, Canada

*Corresponding author: Joselyne Mukantwari. General Nursing Departmenet, Shool of Nursing and Midwifery, College of Medicine and Health Sciences, University of Rwanda, Kigali, Rwanda. Email: mujoselyne@gmail.com,jmukantw@uwo.ca

\section{Abstract}

Nurses within a surgical team play such a fundamental role in the success of a surgery that they require specific training for the purpose. However, in Rwanda, there has been a severe scarcity of perioperative nurses. This article describes the collaborative effort for perioperative nursing training by the University of Rwanda (UR) and the Ministry of Health (MOH) with the Human Resources for Health (HRH) Program and a consortium of American Universities. The goal of the HRH program has been to build up the capacities of health professionals both in academia and clinical settings so as to address the shortage of qualified staff. In that regard, the UR in 2015 started a Masters program in nursing in eight specialties, of which one was perioperative nursing. The aim of this paper is to highlight the training process, success, and challenges of perioperative nursing training in Rwanda.

The training has so far been successful, with the 19 nurses who completed the program working now in academic and clinical teaching institutions. Students in the program have also increased their number of research publications in peer-reviewed journals and international conference presentations. The UR and its partners are investing in the sustainability and excellence of this program. Using the import-of-experts approach to train Rwandans within their country, the program addresses the scarcity of specialists in various disciplines within the nursing profession. As a consequence, countries where the lack of specialized nurses poses challenges may adopt this partnership strategy.

Rwanda J Med Health Sci 2021;4(1):185-196

Keywords: perioperative nursing, training, journey 


\section{Introduction}

Perioperative nursing has been defined by the American Association of perioperative nurses[1] as "the practice of nursing directed toward patients undergoing operative and other invasive procedures"(p.12). In their perioperative patient-focused model, a perioperative nurse is described as "the registered nurse who, using the nursing process, develops a plan of nursing care and then coordinates and delivers care to patients undergoing operative and other invasive procedures. Perioperative nurses have the requisite skills and knowledge to assess, diagnose, plan, intervene, and evaluate the outcomes of interventions" (p.12). Before surgery, a perioperative nurse will assess and prepare surgical patients by addressing their physiological, spiritual, and psychological reactions toward surgery. Intraoperatively, they are most concerned with a patient's safety and that surgery runs smoothly. They anticipate surgical and anesthesia needs and prevent possible complications at different patient treatment stages.[2] After surgery, they continue with recovery and rehabilitation care, combining technical competencies with caring roles.[3] Thus, special training is needed to sustain the safety and surgical care continuum of perioperative patients.[4]
Globally, surgically treatable conditions constitute $11 \%$ of burden of diseases and are among the top 15 causes of disability that could otherwise be effectively treated or prevented through safe and timely surgical care.[5-8] Nurses play an essential role in facilitating surgical care access [5-8] and reducing morbidity and mortality of patients with surgical conditions and associated disabilities. Nursing interventions not only significantly reduce patients' disabilities but also contribute to a decrease in surgical expenses, ultimately reducing the burden of health care costs on a country's economy. $[9,10]$

Even though more than 234 million surgical procedures are globally performed each year, $[6,11]$ less than $10 \%$ of this number are delivered in developing countries. More than 4.8 billion people $(67 \%)$ within the global population do not have access to surgery, and an estimated $95 \%$ of those are from developing countries in Central, Eastern, and Western Sub-Saharan Africa and South Asia. Unfortunately, 143 million surgical procedures are needed each year but not performed in these developing countries.[10]

Rwanda is a small country in subSaharan Africa with a population of 13,108,251 inhabitants.[12] A study[13] indicates that $14.8 \%$ of the total population has experienced 
a surgical disease condition, and a total of $32.9 \%$ of household deaths may have been related to operative conditions. Trauma and injuries alone contribute $23.7 \%$ [14] to $27.5 \%$ [15] of the surgical burden. A safe and timely provision of emergency and essential surgical and anesthesia care is determined by the resources available to and overall flexibility of the healthcare system's workforce and infrastructure in addition to patientassociated factors.[16] Hence, training the surgical staff and establishing suitable infrastructure and equipment will improve access to safe and timely surgery, which remains a significant challenge in developing countries.[5]

About $76.3 \%$ of the Rwandan health system workforce is nurses and midwives [17] who actively participate in government health plans' objectives.[18] In surgery, perioperative nurses play an essential role in providing safe and timely emergency and surgical care, preventing perioperative complications and mortality. Specialized perioperative nursing care tends to enhance the quality of surgical procedures and reduce untoward surgical complications, which are also associated with unnecessary expenses.[9]

Unfortunately, in Rwanda, the number of specialized perioperative nurses is still low given the surgical demand. Hospitals employ nurses with advanced diplomas and a few with bachelor's degrees in general nursing or midwifery. Perioperative skills and knowledge gained from their general nursing and midwifery education are not enough to meet theatre demands and safe surgery requirements.[19] Studies have demonstrated that favourable surgical outcomes are significantly associated with better staffing and nurses' educational preparation.[20] It is in this regard that the Rwandan $\mathrm{MOH}, \mathrm{HRH}, \mathrm{UR}$, and a consortium of American universities collaborated to train nurses at the master's level in eight nursing specialties, including perioperative nursing, to parallel the growth of nursing, anesthesia, and surgery professions in Rwanda.[21]

Rwanda's government employed a multi-year (2012-2019) training approach using tied-aid model partnerships between academic institutions in high- and low-income countries. The selection criteria were based on previous/ongoing effective working relationships with Rwanda or prior expressed interest in working in Rwanda. These institutions also had established reputations as leaders in global health for their respective disciplines or clinical specialties.[22] 
The School of Nursing and Midwifery of the College of Medicine and Health Sciences, UR, therefore, collaborated with Rory Meyers School of Nursing, New York University, to start training in eight specialties, namely nursing education, leadership and management, perioperative, nephrology, critical care and trauma, neonatology, pediatrics, oncology, and medical-surgical nursing. The MOH HRH Program coordinated the partnership for the sake of synchrony and synergy of expertise within the human resource functions within Rwanda.[22]

This article focuses on the perioperative nursing specialty with the intent of describing the specialty training process, its success and associated challenges, and finally, providing recommendations for sustainability.

\section{The perioperative nursing training process}

The training process includes theoretical and clinical components structured around four basic domains essential for carrying out nursing roles and functions responsibly within the perioperative field and ensuring patient safety. These include the ability to: (1) create and maintain a physically safe environment, (2) ensure patients' physiological safety, (3) handle surgical procedures for patients and their families, and (4) maintain patients' individual rights and values. $[23,24]$

The program predicted that graduates would achieve the following attributes: (1) generate and apply advanced knowledge and skills in addressing complex nursing and health-related issues in the perioperative patient care process through evidence-based nursing interventions; (2) initiate, manage and sustain changes that positively affect health outcomes by providing professional leadership during the perioperative patient care process;(3) evaluate the impact of care delivery on health outcomes based on the contributions to the development of nursing knowledge and practice through education, research, scholarly debates, presentations, and publications. $[23,24]$

A diverse team of international experts for quality benchmarking and a team of local experts for content and contextualization developed a three-hundred-credit curriculum for the program much earlier as the first step before training initiation. The curriculum included 80 credits for fundamental modules, 210 core modules, and ten credits for elective modules. The research project carried one-third of the total program credits (Table 1). 
The formal training activities of the program started in 2015 at the University of Rwanda. Training modality included class attendance three days a week from Monday to Wednesday from 8:00 to $17: 00$. In their practicum, the students rotated in three referral and teaching hospitals situated in Kigali, the capital city of Rwanda. The practicum focused on anesthesia and intraoperative and postoperative nursing care. For the dissertation, the students did individual research. The postgraduate studies coordination allocated early in the first semester a senior supervisor (an American or Rwandan holder of a Ph.D.) in pairing with a junior local cosupervisor (MSN graduate) to facilitate students' work on their research proposals, data gathering and analysis, dissertation preparation, and defense in front of a panel. To assess the candidates' performances, the lecturers regularly used individual and group assignments, continuous evaluative tests, and final exams.

Table 1. The curriculum of perioperative nursing training at the UR before review

\begin{tabular}{|c|c|c|c|}
\hline Modules & $\begin{array}{l}\text { Module } \\
\text { Credit }\end{array}$ & $\begin{array}{l}\text { Module } \\
\text { hours }\end{array}$ & Semesters \\
\hline \multicolumn{4}{|l|}{ Common modules } \\
\hline Global Patterns of Health and Illness & 20 & 200 & 1 \\
\hline Research Design and Biostatistics & 20 & 200 & 1 \\
\hline Communication \& Leadership & 20 & 200 & 1 \\
\hline $\begin{array}{l}\text { Nursing Knowledge: Concepts, Theories, } \\
\text { and Practice }\end{array}$ & 10 & 100 & 1 \\
\hline Transforming Nursing Practice & 10 & 100 & 3 \\
\hline $\begin{array}{l}\text { Pathophysiology and Clinical } \\
\text { Management }\end{array}$ & 20 & 200 & 2 \\
\hline Advanced Health Assessment & 10 & 100 & 2 \\
\hline Clinical and Applied Pharmacology & 10 & 100 & 2 \\
\hline \multicolumn{4}{|l|}{ Specialty modules } \\
\hline Focused Clinical I & 20 & 200 & 2 \\
\hline Anesthesia and Post Anesthesia Care & 10 & 100 & 3 \\
\hline Intraoperative Nursing & 20 & 200 & 3 \\
\hline Focused Clinical II & 20 & 200 & 3 \\
\hline Dissertation & 100 & 1000 & 4 \\
\hline Elective module & 10 & 100 & 4 \\
\hline 14 modules & 300 & 3000 & \\
\hline
\end{tabular}




\section{Achievements of the training}

The first cohort comprised 13 candidates, commenced their training on $5^{\text {th }}$ October 2015 and graduated on 25th August 2017. The second cohort of six students also completed their program on $8^{\text {th }}$ November 2019. Eleven out of the 19 graduates work in four university teaching and referral hospitals used for practicums by the University and district hospitals. The remaining seven graduates teach in higher learning institutions, six in the University of Rwanda and one at Ruli Higher Institute of Health. There are eight publications in peerreviewed journals, eleven abstract presentations in international research conferences from their research dissertations, and other manuscripts are underway.
After two years of implementation and following the graduation of the first cohort trained, the teaching team reviewed the curriculum before the second cohort commenced. In conducting this task, the review team was also informed by the recommendations of the experts on critical care. For example, the credits of the Communication and Leadership module as well as Pathophysiology and Clinical Management module were reduced to ten, and the new ten-credit module of Essentials of Perioperative Nursing was created. An additional ten credits were added to Specialized Clinical Focus module (Table 2). The curriculum review and validation were in accordance with the UR and National Council of Nurses and Midwifery regulations.

Table 2. The current curriculum of perioperative nursing training at the UR (after review)

\begin{tabular}{llll}
\hline Modules & $\begin{array}{l}\text { Module } \\
\text { Credits }\end{array}$ & Module hours & Semesters \\
\hline Common modules & 20 & 200 & 1 \\
$\begin{array}{l}\text { Global Patterns of Health and } \\
\text { Illness }\end{array}$ & 20 & 200 & 1 \\
Research Design and Biostatistics & 10 & 100 & 1 \\
Communication \& Leadership & 10 & 100 & 1 \\
Nursing Knowledge: Concepts, & & 100 & 3 \\
Theories, and Practice & 10 & 100 & 2 \\
Transforming Nursing Practice & 10 & & \\
$\begin{array}{l}\text { Pathophysiology and Clinical } \\
\text { Management }\end{array}$ & & & \\
\hline
\end{tabular}




\begin{tabular}{llll}
\hline Advanced Health Assessment & 10 & 100 & 2 \\
Clinical and Applied Pharmacology & 10 & 100 & 2 \\
Specialty modules & & & \\
Essentials of Perioperative Nursing & 10 & 100 & 2 \\
Perioperative Nursing Clinical I & 20 & 200 & 2 \\
Anesthesia and Post Anesthesia & 10 & 100 & 3 \\
Care & & & \\
Intraoperative Nursing & 20 & 200 & 3 \\
Perioperative Nursing Clinical II & 30 & 300 & 3 \\
Dissertation & 100 & 1000 & 4 \\
Elective course & 10 & 100 & 4 \\
\hline 14 modules & $\mathbf{3 0 0}$ & $\mathbf{3 0 0 0}$ & \\
\hline
\end{tabular}

The current class (2019-2021) comprises three students: two are from referral hospitals in Rwanda, while the remaining one is from a district hospital.

\section{Benefits of the program}

Patients undergoing surgery are normally at risk related to the surgical procedure, or/and anesthesia, and the nurses play a critical role in providing patients with care in the perioperative period.[5-8] It is therefore imperative to invest in high levels of trained perioperative nurses to enhance surgical safety and to promote cost-effective care innovations through research and evidence-based practice. The current perioperative nurse training entails nursing care of surgical patients in the various surgical disciplines, i.e., neurosurgery, orthopedic surgery, cardiothoracic and vascular surgery, and plastic surgery. These disciplines have trained doctors and anesthetists but lack properly trained perioperative nurses and function only with nurses trained on the job. With the advanced training of perioperative nurse specialists, the hospitals in Rwanda will offer safe, specialized services and care. For example, most Rwandans with cardiothoracic and vascular conditions seek treatment abroad, which could be diminished if we invest and exploit specialized training of perioperative nurses to work alongside the trained doctors and anesthetists.

\section{Challenges of the program}

The number of candidates attending perioperative training is decreasing progressively. Candidates admitted in the third and the second cohort of students were low compared to the first cohort. The lack of scholarships to meet the escalating cost of 
education, and the failure to secure a study leave from the workplace have been the main reasons for reduced numbers. With regard to the trainers, the program relies on expatriates hired through the Ministry of Health and American universities' partnership under the HRH program. Despite the cost spent on their training and the gap in perioperative nursing skills, the graduates who are working in Rwandan hospitals were not considered for promotions in their specialization. The underemployment continues to discourage new candidates from enrolling in training. As long as the health system does not address the underemployment problems of the graduates of the program, it will be challenging to overcome the countrywide gap in specialized perioperative nursing.

\section{Training sustainability}

To ensure that the program becomes sustainable, the UR has recruited outstanding graduates from the program to join the staff training the second cohort of master's students. In this regard, the University has adopted the mentorship strategy of pairing local faculty and training experts to equip the mentees with the skills and knowledge needed for practice, research, and improving health care in clinical settings. In addition, to mitigate the challenges, the University has considered international students' entry into the master's programs, has attempted to look for donors to partner with, and has also engaged in grant applications. The recent grant applications were for DAAD (German Academic Exchange Service) host institutions incountry/in-region scholarship program and Clinton Health Access Initiative (CHAI) program.

The school of Nursing and Midwifery has initiated a Ph.D. program for upward mobility and professional growth of the master's graduates. Some of the faculty members have completed their Ph.D. programs outside and within Rwanda, while others are still training perioperative nurses to sustain the activity and direction for perioperative nursing in Rwanda.

\section{Conclusion and}

\section{recommendations}

Overall, the program has been successful, despite the challenges being encountered. Other teaching institutions from developing countries can also implement such partnerships to address the shortage of specialized nurses. Nevertheless, concerted effort from different entities could contribute to the success of perioperative nurses' training and overcome the gap still existing in delivering perioperative 
nursing care and safe surgery. The Ministry of health, hospitals, and other health facilities will need to facilitate the candidates' training in the master's program and promote the graduates into positions that positively change perioperative practices.

Successful and quality surgery depends entirely on the surgical team spirit emanating from all the trained surgical team members as specialists. Thus, perioperative nurses should be involved in decision-making and quality improvement undertakings. The University will require to continue advocacy for funding and scholarship opportunities to assist students in their studies, improve the enrolment rate and thereby contribute to overcoming the country gap of perioperative nurses. Further research to assess the clinical impact of having specialized perioperative nurses in the Rwandan health workforce will shed light on the outcome of the training engagement of perioperative nurses.

\section{Acknowledgment}

We express our sincere gratitude to the Rwandan government, especially the Ministry of Health, University of Rwanda, American universities, Human resources for Health program, and national and international experts who contributed to initiating, funding and implementing the program until now.

\section{Author's contribution}

JM, LO and DR :Curriculum implementation, conception and drafting of the manuscript, review, and approval of the manuscript

\section{Declaration of conflict of interest}

This is our experience in the training of perioperative nurses in Rwanda. Therefore, we declare no conflict of interest.

\begin{abstract}
This article is published open access under the Creative Commons Attribution-NonCommercial NoDerivatives (CC BYNC-ND4.0). People can copy and redistribute the article only for noncommercial purposes and as long as they give appropriate credit to the authors. They cannot distribute any modified material obtained by remixing, transforming or building upon this article. See https://creativecommons.org/licenses/by-ncnd/4.0/
\end{abstract}

\section{References}

1. Nagle GM. Perioperative Nursing. Nursing Clinics of North America. 2006;41:1-5.

2. Goodman T, Spy C. Essentials of Perioperative Nursing [Internet]. Sixth edition. World Hqrs. Burlington: Jones \& Bartlett Learning; 2017. Available from: http://lccn.loc.gov/20160012 82

3. Blomberg AC, Bisholt B, Nilsson J, Lindwall L. Making 
the invisible visible - operating theatre nurses' perceptions of caring in perioperative practice. Scandinavian Journal of Caring Sciences.2015;29:361-8.

4. Leyden K, Dufrene C, Land S. Introducing Perioperative Nursing as a Foundation for Clinical Practice. AORN Journal [Internet]. Elsevier; 2017;106:121-7. Available from:

http://dx.doi.org/10.1016/j.a orn.2017.06.004

5. Kennedy ED, Fairfield CJ, Fergusson SJ. A neglected priority. The importance of surgery in tackling global health inequalities. 2015;5:16.

6. World Health Organization. Strengthening emergency and essential surgical care and anaesthesia as a component of universal health coverage Report by the Secretariat. Provisional agenda item 51 [Internet]. 2014;2002:16-8. Available from: http://apps.who.int/gb/ebwh a/pdf_files/EB135/B135_3en.pdf

7. Forrester JD, Forrester JA, Kamara TB, Groen RS, Shrestha S, Gupta S, et al. Self-reported Determinants of Access to Surgical Care in 3
Developing Countries. JAMA Surgery [Internet]. 2016;151:257. Available from: http://archsurg.jamanetwork. com/article.aspx?doi $=10.1001$ /jamasurg.2015.3431

8. Nakul Raykar JS, Ng-Kamstra S, Saluja JWS, Anderson GA, Meara JG, Tefera G, et al. Progress in achieving universal access to surgical care: An update and a path forward [Internet]. Bull. World Health Organ. 2016 [cited 2017 Sep 28]. Available from: http://bulletin.facs.org/2016 /06/progress-in-achievinguniversal-access-to-surgicalcare-an-update-and-a-pathforward

9. Ball JE, Bruyneel L, Aiken LH, Sermeus W, Sloane DM, Marie $\mathrm{A}$, et al. Post-operative mortality, missed care and nurse staffing in nine countries: A cross-sectional study. International Journal of Nursing Studies. 2017;1:10-5.

10. Raykar N, Mukhopadhyay S, Ng-Kamstra JS, Lin Y, Saluja S, Scott JW, et al. Progress in achieving universal access to surgical care: An update and a path forward [Internet]. Essent. Surg. care. 2016 [cited 2017 Sep 28]. Available from: http://bulletin.facs.org/2016 /06/progress-in-achieving- 
universal-access-to-surgicalcare-an-update-and-a-pathforward/

11. World Health Assembly. "Item 17.1: $\quad$ Strengthening emergency and essential surgical care and anaesthesia as a component of universal health coverage". Minutes of the Sixty-Eighth World Health Assembly meeting 26 May 2015, WHO, Geneva. 2015.

12. United Nations. Rwanda Population (LIVE) [Internet]. worldometers population. 2020 [cited 2020 Dec 29]. Available from:

https: / /www.worldometers.inf o/world-population/rwandapopulation/

13. Petroze R, Groen R, Niyonkuru F, Mallory $M$, Ntaganda E, Joharifard S, et al. Estimating operative disease prevalence in a lowincome country: Results of a nationwide population survey in Rwanda. Surgery [Internet]. 2013;153:457-64. Available from:

https://www.ncbi.nlm.nih.gov / pubmed/?term=Estimating+ operative+disease+prevalence + in $+a+$ lowincome + country $\% 3 \mathrm{~A}+$ Results + of $+a+$ nationwide+population + survey+in+Rwanda

14. Ntakiyiruta G, Wong EG,
Rousseau MC, Ruhungande L, Kushner AL, Liberman AS, et al. Trauma care and referral patterns in Rwanda: Implications for trauma system development. Canadian Journal of Surgery. 2016;59:35-41.

15. Petroze RT, Joharifard S, Groen RS, Niyonkuru F, Ntaganda E, Kushner AL, et al. Injury, disability and access to care in Rwanda: Results of a nationwide crosssectional population study. World Journal of Surgery. 2015;39:62-9.

16. Ozgediz D, Jamison D, Cherianc M, McQueen K. The burden of surgical conditions and access to surgical care in low- and middle-income countries. Bull World Health Organ. 2008;86:646-7.

17. Rwanda Ministry of Health. National human resources for health policy [Internet]. kigali: $\mathrm{MOH}$; 2014. Available from: http://www.moh.gov.rw/filea dmin/templates/policies/Hu man_Ressource_for_Health_Po licy.pdf

18. Maryland MA, Aurelie N. Advancing clinical nursing excellence in Rwanda; A management perspective. $J$ Nurs Care. 2014;3:4172. 
19. Ryamukuru D, Mukantwari J, Omondi L, Karonkano GR, Munyaneza E, Karera E, et al. Clinical experiences of perioperative nursing Masters Students in selected Rwandan Referral Hospitals. Rwanda Journal of Medicine and Health Sciences. 2018;1:34-8.

20. Friese CR, Lake ET, Aiken LH, Silber JH, Sochalski J. Hospital nurse practice environments and outcomes for surgical oncology patients. Health Services Research. 2008;43:1145-63.

21. Mukamana D, Karonkano GR, Rosa W. Advancing Perioperative Nursing in Rwanda Through Global Partnerships and Collaboration. AORN J [Internet]. 2016;006. Available from:

https: / /aornjournal.onlinelibr ary.wiley.com/doi/pdf/10.101 6/j.aorn.2016.10.006
22. Cancedda C, Cotton P, Shema J. Health Professional Training and Capacity Strengthening Through International Academic Partnerships: The First Five Years of the Human Resources for Health Program in Rwanda. Int $J$ Heal Policy Manag. 2018;7:1024-1039.

23. Meara, John G et al. Surgery and Global Health: Lancet Commission. Lancet. 2014;383:12-4.

24. Morrison JD. Evolution of the Perioperative Clinical Nurse Specialist Role. AORN Journal. 2019;72:227-32. 